\title{
Endobiliary radiofrequency ablation through an EUS-guided hepaticogastrostomy fistula for hilar malignant biliary stenosis
}

In a 75-year-old man with hilar cholangiocarcinoma ( $\mathbf{F i g . 1}$ ), a plastic stent was deployed in the right hepatic duct. Left hepatic duct drainage using ERCP was difficult due to ductal stenosis. Thus, EUS-guided hepaticogastrostomy (EUS-HGS) was performed (> Fig. 2).

Because the cholangitis relapsed 5 months after EUS-HGS, stent-in-stent (SIS) deployment of SEMS was considered. After SIS deployment of SEMS, endobiliary RFA was expected to be difficult. Therefore, endobiliary RFA was performed in anticipation of a longer patency period before SEMS deployment.

A guidewire was placed through the EUSHGS fistula. An endobiliary RFA catheter (Habib EndoHPB Catheter, Boston Scientific Corporation, Marlborough, Massachusetts, United States) was guided to the stenosis site, which was ablated for 90 seconds through the EUS-HGS fistula (VIO 200 D, Effect8, 7W, Erbe Elektromedizin $\mathrm{GmbH}$, Tubingen, Germany) ( $>$ Fig.3). An uncovered SEMS (HANAROSTENT uncover, M.I TECH, Gyeonggi, Korea) was deployed through the fistula. After that, a plastic stent (Thorough and Pass Type IT, GADELIUS MEDICAL, Tokyo, Japan) was inserted into the EUS-HGS fistula after SEMS deployment to maintain the EUS-HGS fistula. ERCP was then performed. A guidewire was inserted into the right hepatic duct and another uncovered SEMS (ZEOSTENT V, Zeon Medical Inc., Tokyo, Japan) was deployed therein ( $>$ Fig.4, $>$ Video $\mathbf{1}$ ). There was

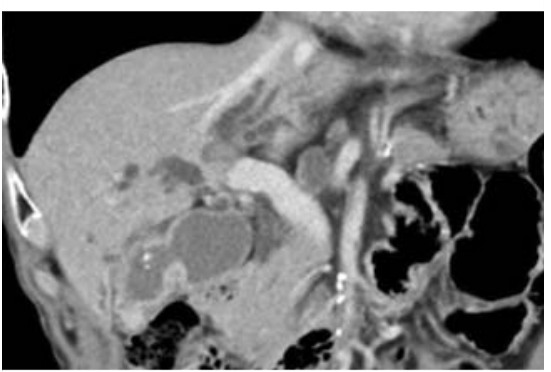

- Fig. 1 Contrast-enhanced computed tomography revealed a hilar cholangiocarcinoma.

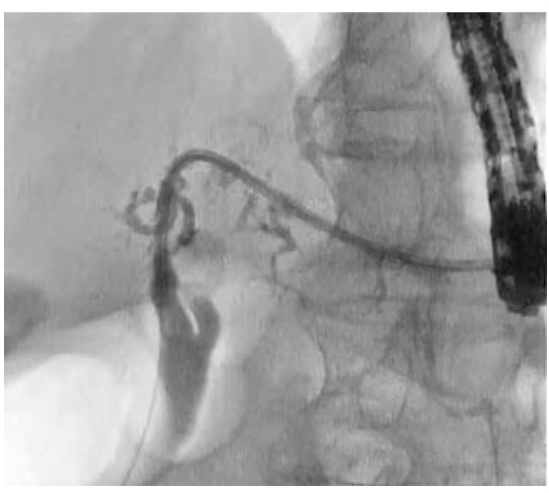

- Fig. 3 An endobiliary radiofrequency ablation catheter was guided to the stenosis site, which was ablated for $90 \mathrm{sec}-$ onds.

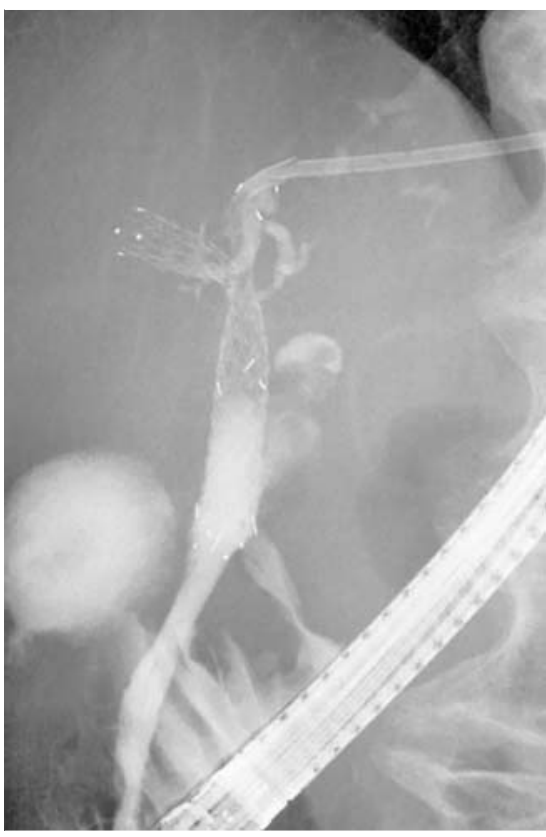

\section{Conclusions}

Reintervention was possible through the EUS-BD fistula. Endobiliary RFA from the EUS-BD fistula is effective when the guidewire from the transpapillary approach cannot pass the biliary stricture.
- Fig. 4 Stent-in-stent deployment of self-expandable metallic stent was performed. 


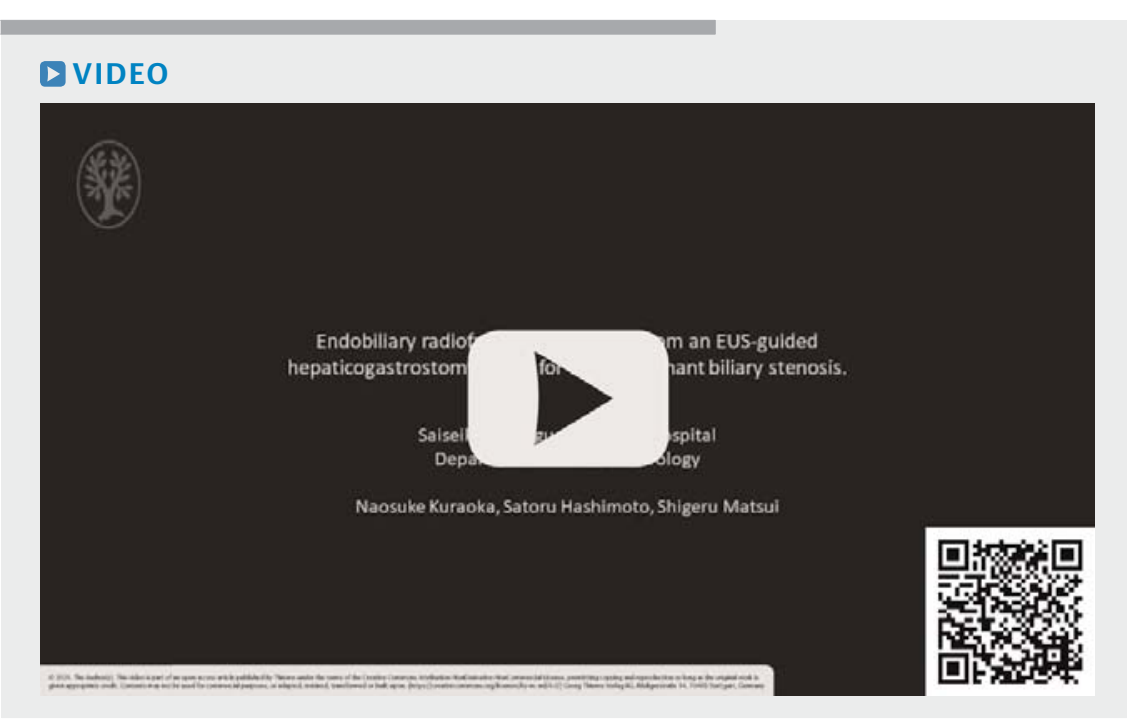

- Video 1 After cholangiography of the fistula site, the stenosis was ablated. An uncovered SEMS was deployed through the fistula. Then, another uncovered SEMS was deployed in the right hepatic duct with transpapillary ERCP.

\section{Competing interests}

The authors declare that they have no conflict of interest.

The authors

\section{Naosuke Kuraoka, Satoru Hashimoto,} Shigeru Matsui

Department of Gastroenterology, Saiseikai Kawaguchi General Hospital

\section{References}

[1] Cho JH, Jeong S, Kim EJ et al. Long-term results of temperature-controlled endobiliary radiofrequency ablation in a normal swine model. Gastrointest Endosc 2018; 87: 1147-1150

[2] Lee YN, Jeong S, Choi HJ et al. The safety of newly developed automatic temperaturecontrolled endobiliary radiofrequency ablation system for malignant biliary strictures: A prospective study. J Gastroenterol Hepatol 2019; 34: 1454-1459

[3] Larghi A, Rimbas M, Tringali A et al. Endoscopic radiofrequency biliary ablation treatment: A comprehensive review. Dig Endosc 2019; 31: 245-255

[4] Inoue T, Ito K, Yoneda M. Antegrade radiofrequency ablation and stenting for biliary stricture thorough endoscopic ultrasoundguided heapticogastrostomy. Dig Endosc 2018; 30: 793-794

[5] Inoue T, Ibusuki M, Kitano R et al. Endoscopic ultrasound-guided antegrade radiofrequency ablation and metal stenting with hepaticoenterostomy for malignant biliary obstruction: a prospective preliminary study. Clin Transl Gastroenterol 2020; 11: e00250

\section{Naosuke Kuraoka, MD, PhD}

Department of Gastroenterology, Saiseikai Kawaguchi General Hospital, 5-11-5

Nishikawaguchi, Kawaguchi, Saitama, 332-8558, Japan

Fax: +81-48-256-5703

kuraoka0926@gmail.com

\section{Bibliography}

Endosc Int Open 2021; 09: E699-E700

DOI 10.1055/a-1393-5497

ISSN 2364-3722

(c) 2021. The Author(s).

This is an open access article published by Thieme under the terms of the Creative Commons Attribution-NonDerivativeNonCommercial License, permitting copying and reproduction so long as the original work is given appropriate credit. Contents may not be used for commercial purposes, or adapted, remixed, transformed or built upon. (https:// creativecommons.org/licenses/by-nc-nd/4.0/)

Georg Thieme Verlag KG, Rüdigerstraße 14, 70469 Stuttgart, Germany 